\title{
Study of Increase in Hemoglobin Concentration after Administration of Intravenous Iron Sucrose in Pregnant Women with Severe Anemia
}

\author{
Anita Kumari ${ }^{1}$, Sangeeta Rai $^{2}$, Shyama $^{3}$
}

\begin{abstract}
Introduction: Iron-deficiency anemia is a great concern among obstetricians. Anemic women are at a greater risk of dying during their pregnancy. Despite the measures taken to control anemia in pregnancy in the last two decades, the severity of nutritional anemia continues to remain a public health issue of great magnitude. Oral supplement or iron has several drawbacks. Hence an idea was conceptualized to conduct a study to evaluate the efficacy of IV iron sucrose (OROFER-S) in the improvement of hemoglobin concentration in the antenatal mothers with severe anemia.

Materials and methods: This progressive study was conducted in antenatal OPD of obstetrics and gynecology department of VSS Medical College, Burla, Odisha for a period of 24 months.

Results: Out of 23 antenatal mothers with severe anemia, $73.91 \%$ were residing in rural area and $26.08 \%$ were residing in urban area. The cases recruited in the study were given a total of $300 \mathrm{mg}$ elemental iron as iron sucrose complex diluted in $0.9 \%$ of NS per week. Hemoglobin level was estimated at the onset and again two weeks after the completion of the study. On completion of therapy, there was significant improvement in $\mathrm{Hb}$ level with a rise of $\mathrm{Hb}$ level (2.5-3) in $4.3 \%$ mothers, and (1.5-2) $\mathrm{g} / \mathrm{dL}$ in $60.66 \%$ cases. No rise in $\mathrm{Hb}$ level was observed in $8.6 \%$ cases. Present study shows correlation between severity of anemia and gravidity with multigravida accounting for $65.21 \%$. Most of the patients (39.13\%) were just literate or had primary education (26.08\%). The study groups faced only minor side effects like nausea (21.73\%), shivering (13.04\%), no serious anaphylactic reactions were observed. Low birth weight $(47.82 \%)$ is the most common fetal complication. Further IUGR accounts for $34.78 \%$ and premature labor (13.04\%). Gestational hypertension (21.73\%), postpartum hemorrhage (17.39\%) and preterm labor (3.90\%) and the common maternal complications observed.

Keywords: Intravenous iron-sucrose, Pregnancy, Severe anemia.

World Journal of Anemia (2018): 10.5005/jp-journals-10065-0039
\end{abstract}

\section{INTRODUCTION}

Anemia is the commonest medical disorder in pregnancy. More than half a million maternal deaths occur each year, approximately $90 \%$ of which are in developing country. ${ }^{1}$

Anemia in pregnancy is defined by the World Health Organization as a hemoglobin $(\mathrm{Hb})$ value below $11 \mathrm{~g} / \mathrm{dL}$ and a hematocrit of $<0.33$. The Indian Council of Medical Research (ICMR) uses further categories of anemia depending on hemoglobin levels. ${ }^{1}$

Prevalence of anemia is estimated to be about $40 \%$ of world's population. Nearly half of the global total number of anemic women live in India subcontinent and, in India alone, the prevalence of anemia during pregnancy may be as high as $88 \%$ with iron deficiency being commonest cause worldwide. ${ }^{2}$

In developing countries, anemia in pregnancy is frequent and has been attributed to poor nutrition and high incidence of concurrent disease, and can potentially complicated mortality in developing countries. There is evidence indicating that maternal hemoglobin level under $7 \mathrm{~g} / \mathrm{dL}$ is associated with higher risk in mother of developing heart failure, which has adverse consequence on the mother and fetus (Figs 1 to 3 ). ${ }^{1}$

These are various possible forms of treatment for irondeficiency anemia. Iron can be given by mouth, by intramuscularly (IM) injection of intravenous (IV) injection. ${ }^{1}$

Oral iron is often preferred route of administration for mild anemia, while IM and IV routes are more frequently used in people with severe anemia when the risk of cardiac failure due
${ }^{1}$ Department of Obstetrics and Gynecology, Central Superspeciality Hospital, ECR, Patna, Bihar, India

${ }^{2}$ Department of Obstetrics and Gynecology, Banaras Hindu University, Varanasi, Uttar Pradesh, India

${ }^{3}$ Department of Medicine, All India Institute of Medical Sciences, Patna, Bihar, India

Corresponding Author: Anita Kumari, Department of Obstetrics and Gynecology, Central Superspeciality Hospital, ECR, Patna, Bihar, India, Phone: +91 9830283188, e-mail: dranita1979@gmail.com

How to cite this article: Kumari A, Rai S, Neeraj S. Study of Increase in Hemoglobin Concentration after Administration of Intravenous Iron Sucrose in Pregnant Women with Severe Anemia. World J Anemia 2018;2(3-4):79-84.

Source of support: Nil

Conflict of interest: None

to severe anemia are perceived to out weight the risk of potential adverse effects. ${ }^{1}$ Parenteral iron preparations available are iron dextral complex, iron sorbitol citric acid complex or iron sucrose complex. Since age old whether oral or parenteral preparation of iron increases the $\mathrm{Hb}$ after around 3 weeks. So parenteral iron even the total close iron (TDI) does not help in increase of hemoglobin for emergency or pregnancy at term. ${ }^{2}$

We are in search of an iron preparation which can increase the hemoglobin in a shorter period may be 5-7 days. Therefore we have

o The Author(s). 2018 Open Access This article is distributed under the terms of the Creative Commons Attribution 4.0 International License (https://creativecommons. org/licenses/by-nc/4.0/), which permits unrestricted use, distribution, and non-commercial reproduction in any medium, provided you give appropriate credit to the original author(s) and the source, provide a link to the Creative Commons license, and indicate if changes were made. The Creative Commons Public Domain Dedication waiver (http://creativecommons.org/publicdomain/zero/1.0/) applies to the data made available in this article, unless otherwise stated. 


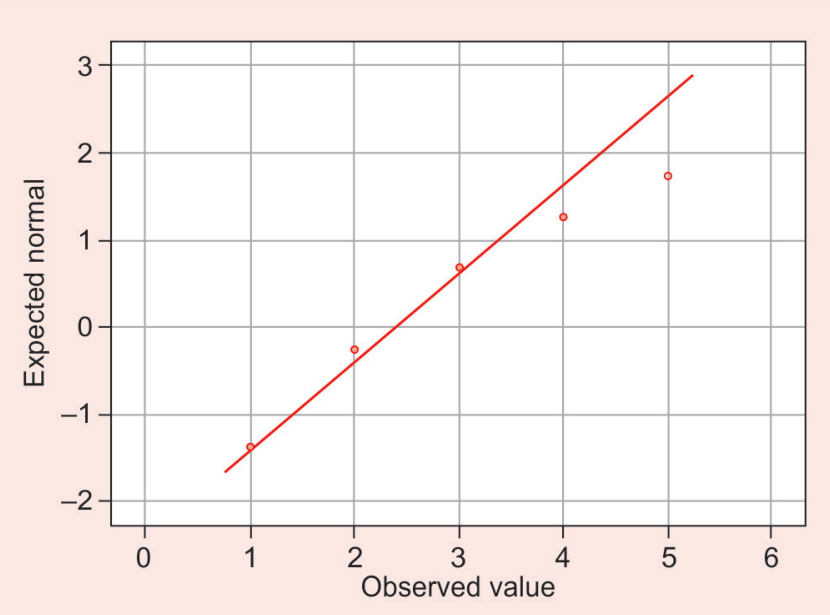

Fig. 1: Q-Q graph for age (Table 1)

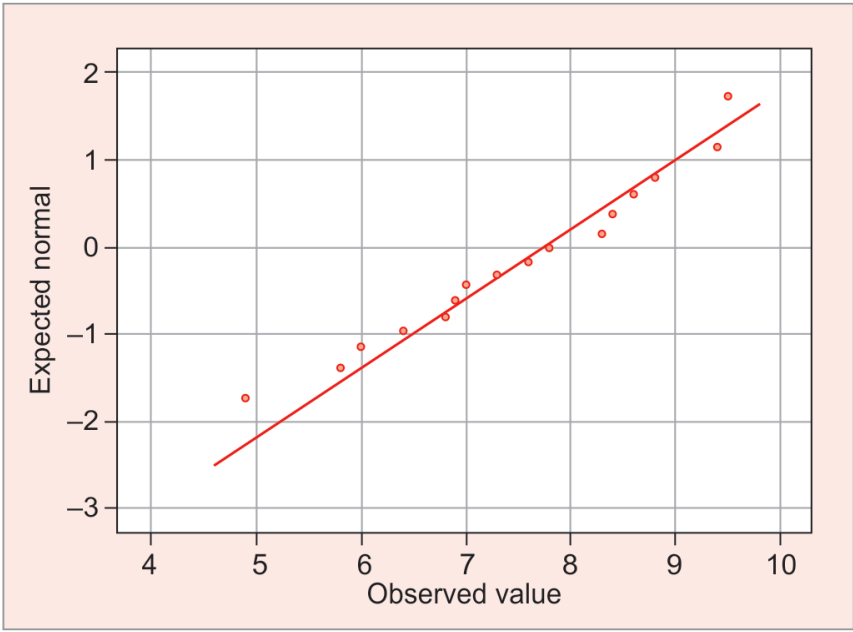

Fig. 3: Q-Q graph post-Fe (Table 2)

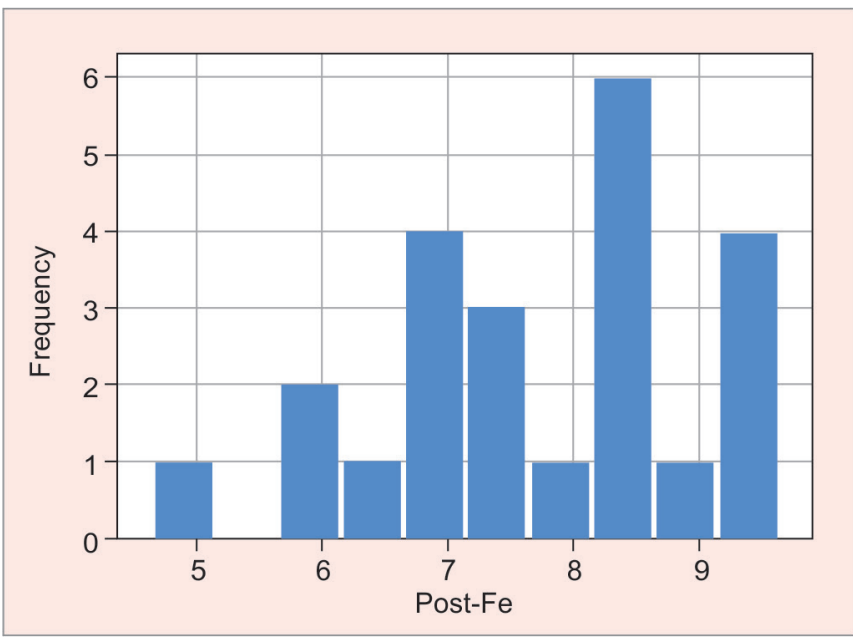

Fig. 5: Post-Fe (Table 2)

chosen iron sucrose complex to see the result mainly in respect of the time taken for increase of hemoglobin. ${ }^{3}$

Elemental iron needed $(\mathrm{mg})=($ normal $\mathrm{Hb}-$ patients $\mathrm{Hb}$ $\times$ weight $(\mathrm{kg}) \times 2.21+1,000)$

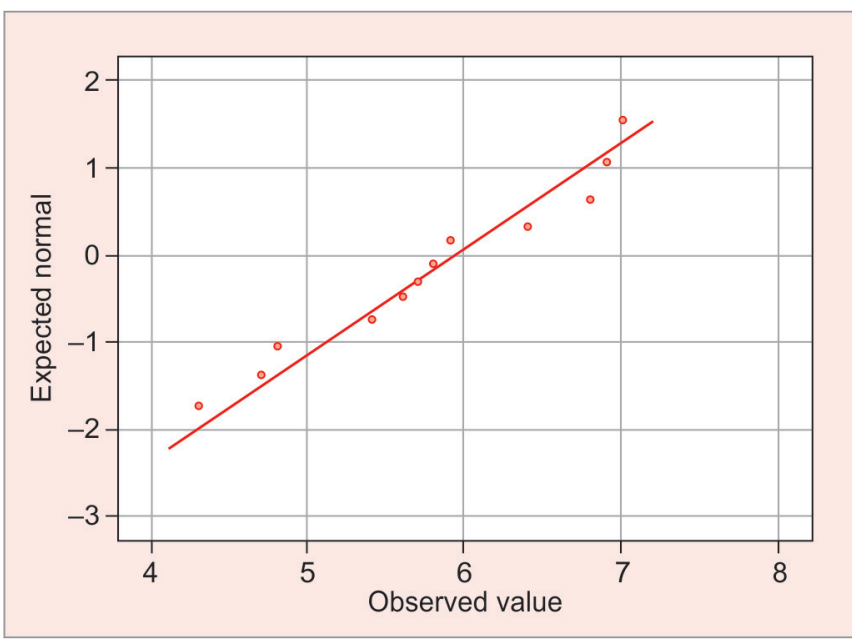

Fig. 2: Q-Q graph for pre-Fe (Table 2)

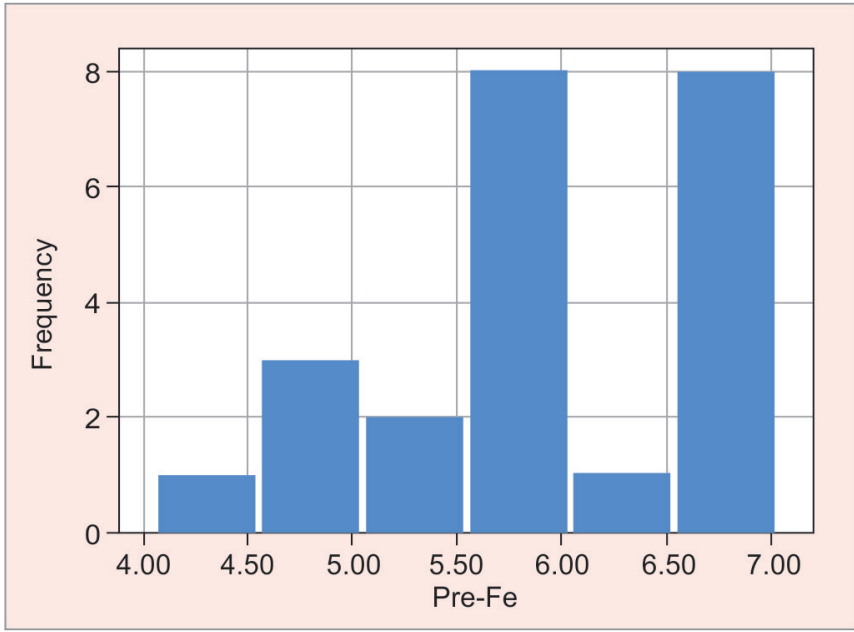

Fig. 4: Pre-Fe (Table 2)

All IV iron agents consist of spheroidal nanoparticles in which a core of iron oxyhydroxide gel is surrounded by a shell of carbohydrate that stabilized the iron oxyhydroxide, slows the release of bioactive iron and maintains the particles in colloidal suspension. After injection, the particles mix with plasma, enter the reticuloendothelial system and are taken up by phagocytes in the liver, spleen and bone marrow, thus, the iron is released into an iron pool, from which it is either incorporated by ferritin into intracellular iron stores or released from the cells and taken up by transferring for delivery to erythroid precursors. ${ }^{4}$

Despite cost, side effect and invasive nature of IV iron therapy, there is considerable history of their safe and effective use, though usually confined to the second and third trimesters (Figs 4 to 6$)^{4}{ }^{4}$

The place of IV iron therapy has been variously defined in condition: ${ }^{4}$

- Nonresponse to oral iron and severe anemia during pregnancy and puerperium.

- Alternative to oral in pregnant women with severe iron deficiency in the third trimester.

- Inability to tolerate side effects of oral iron, inflammatory bowel disease, peptic ulcer, noncompliance documented iron malabsorption. 


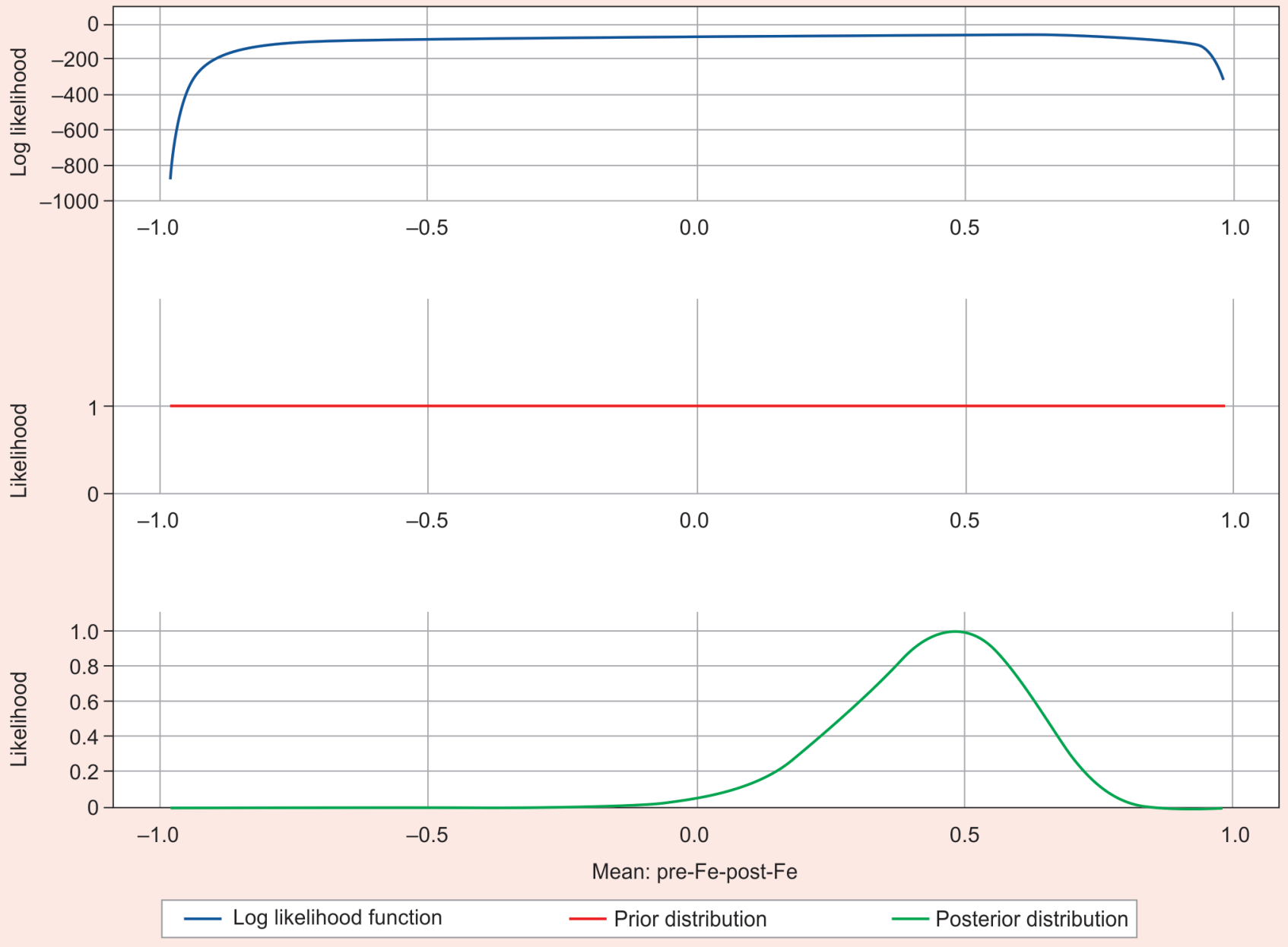

Fig. 6: Pre-post Fe distribution and likelihood fraction

- Second options if oral iron fails to increase $\mathrm{Hb}$ in two weeks, first option if $\mathrm{Hb}<9 \mathrm{~g} / \mathrm{L}$ beyond 14 weeks of gestation; first option in third trimester.

- Requirement for emergency supplementation, contraindication to blood transfusion, chronic blood loss, combination with recombinant human erythropoietin.

Intravenous infusion should be given in hospital setting with injection epinephrine, hydrocortisone and oxygen always available in the event of anaphylactic reaction. In case of any reaction in the form of chest pain, rigor, chills, fall in blood pressure, dyspnea, hemolysis and anaphylactic reaction infusion should be stopped and antihistaminic, corticoids and epinephrine given. ${ }^{5}$

\section{Materials and Methods}

The present study was conducted on pregnant women with severe anemia attending antenatal OPD of V.S.S. Medical College, Burla, Sambalpur, for a period of 24 months from September 2014 to September 2016.

\section{Study Group}

\section{Inclusion Criteria}

- All pregnant women with $\mathrm{Hb}$ concentration $<7 \mathrm{~g} / \mathrm{dL}$.

- Noncompliant/cannot be relied to take oral iron.
- Documented iron malabsorption.

- Suffers from inflammatory bowel disease.

\section{Exclusion Criteria}

- Pregnant women associated with allergic reactions with iron therapy.

- With $\mathrm{Hb}>7 \mathrm{mg} / \mathrm{dL}$.

\section{Sample Size}

To be determined as per statistical sampling methods.

\section{Methodology}

- All pregnant women $\mathrm{Hb}<7 \mathrm{~g} / \mathrm{dL}$ admitted through OPD or emergency ward will be included in the study.

- Detailed history regarding age, duration of marriage, socioeconomic conditions including family income, literacy status, residential status and obstetric history were recorded.

- Mothers were explained about the importance of iron supplementation, side effects and cost of injectable iron formulation.

- Prior to any supplementation, necessary investigations and evaluation are done as per Performa. $\mathrm{Hb}$ was estimated by Saheli's method done at Regional Diagnostic Centre, VSS MCH. 
- Precautions like those of blood transfusion are to be taken both prior to and during the infusion process.

- Injectable iron (Orofer-S) instituted by dissolving 1 ample ( $1 \mathrm{amp}=100 \mathrm{mg}$ ) with $500 \mathrm{~mL}$ of $0.9 \%$ normal saline. If amount is $>50 \mathrm{~mL}$, then the total dose is infused on two consecutive days, infusing half the total amount on each day and given slowly@10 drops/minutes initially. If no reaction occurs, drip rate is increased @40 drops/minute.

- Any adverse reaction like chest pain, rigor, hypotension occurs, omission of the drip is done.

- Finally, blood is tested for the rise in $\mathrm{Hb}$ concentration and the same dose is repeated next week if $\mathrm{Hb}$ concentration is less than the desired level.

- These women were followed up till delivery and birth weight of the infant, mode of delivery and any adverse pregnancy outcome recorded.

\section{Results}

\section{Age Descriptive}

The no. of antenatal cases presenting with severe anemia were maximum in the age group $20-24$ years (47.825\%) with decreased incidence, i.e., $26.086 \%$ in the age group of $25-29$ years, $8.600 \%$ in the age group of $30-34$ years and $4.340 \%$ in the age group of $\geq 35$ years. Mean-2.3913; std. error-0.20603; 95\% confidence interval for mean lower bound-1.9640, upper bound-2.8186; median--2.0000; std. deviation-0.98807 (Table 1).

\section{Pre (Pre-Fe) and Post (Post-Fe) Iron}

Table 2 shows the absolute rise in hemoglobin level of $(2.5-3 \mathrm{~g} / \mathrm{dL})$ after IV iron supplementation in 14 out of 23 mothers $(60.86 \%)$, in 6 out of 23 mothers (26.08\%), rise in hemoglobin was found

Table 1: Age distribution of antenatal mother with severe anemia

\begin{tabular}{lcc}
\hline Age group in years & No. of patients & Percentage \\
\hline $15-19$ & 3 & 13.4 \\
$20-24$ & 11 & 47.82 \\
$25-29$ & 6 & 26.086 \\
$30-34$ & 2 & 8.6 \\
$\geq 35$ & 1 & 4.34 \\
\hline
\end{tabular}

Table 2: Distribution of patients according to rise in hemoglobin level after IV iron sucrose supplementation

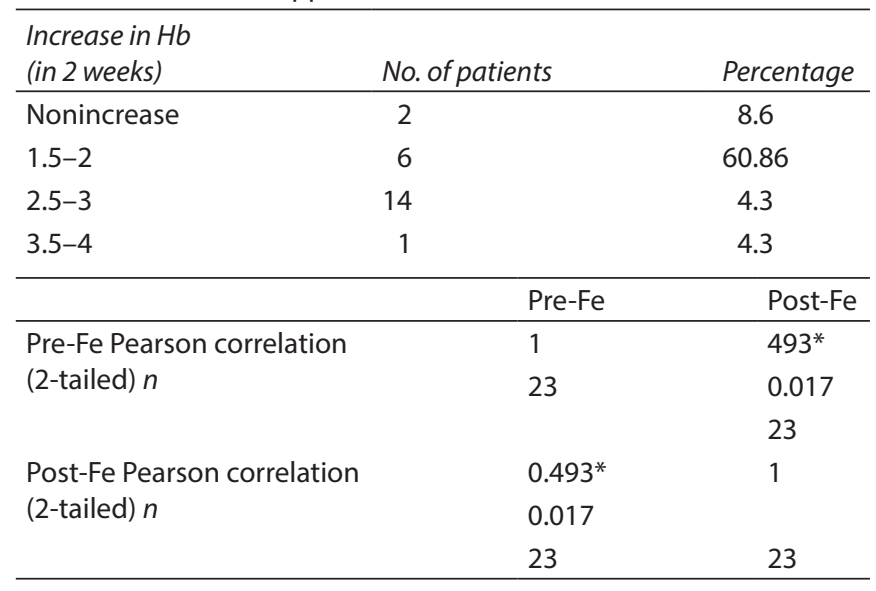

${ }^{*}$ Correlation is significant at the 0.05 level (2-tailed) to be 1.5 to $2 \mathrm{~g} / \mathrm{dL}$. There is only 1 out of 23 (4.3\%) cases with rise of hemoglobin of $3.5-4 \mathrm{~g} / \mathrm{dL}$. No rise of hemoglobin level was observed in 2 out of 23 (8.6\%) mothers. PREFE statistics mean5.9522; std. error-0.17227; $95 \%$ confidence interval for mean (upper bound-6.3095, lower bound-5.5949); median-5.8000; variance $-0.683 \mathrm{std}$. deviation- 0.82620 Post-Fe statisticsmean-7.7435; std. error-0.26374; 95\% confidence interval for mean (upper bound-8.2904, lower bound-7.1965; median7.8000; variance-1.600, std. deviation-1.26485 $t$ test for pre-Fe and post-Fe (paired samples statistics)-pre-Fe-mean-5.9522 $(n=23)$; SD-0.82620; SE-0.17227; post-Fe-mean-7.7435 $(n=23)$; SD-1.26485; SE-0.26374; pre-Fe and post-Fe- $(n=23)$ correlation-0.493; significance-0.017).

The no of antenatal patients with severe anemia were 64 out of which only 23 (35.93\%) patients were given IV iron therapy and were recruited in the study (Table 3). In this study out of 8,390 antenatal cases, 432 were randomly screened for anemic status based on $\mathrm{Hb}$ level during their first visit to OPD, 143 (33.01\%) were found to be nonanemic and 289 were anemic. Among the anemic cases, 137 (31.71\%) were mildly anemic, 88 (20.37\%) moderately anemic, 64 (14.81\%) severely anemic (Table 4). Among the antenatal cases with severe anemia, $73.91 \%$ belongs to rural area and $26.08 \%$ belongs to urban area, this is shown in (Table 5). In this study 16 out of 23 $(69.56 \%)$ antenatal cases with severe anemia has family income less than Rs. 1,500/month. 6 out of 23 (26.08\%) cases had family income below 1,500-5,000/month. 1 out of 23 (4.34\%) mothers belong to middle income and above with family income $\geq$ Rs. 5,000/month (Table 6). The above table shows that most of the mothers, 9 out of $23(39.13 \%)$ were just literate. The number of antenatal cases who were having primary education 6 out of $23(26.08 \%)$, secondary education was 4 out of $23(17.39 \%) .1$ out of 23 (8.6\%) were having secondary education and above (Table 7). Most of antenatal mother with severe anemia were multigravida, i.e., 15 out of $23(65.21 \%)$ and only 8 out of $23(34.78 \%)$ were primigravida (Table 8). Among the antenatal cases receiving IV iron therapy 5 out of $23(21.73 \%)$ complained of nausea and 3 out of $23(13.4 \%)$ suffered from shivering. Rest 15 out of 23 (65.3\%) cases had no side effect (Table 9). The incidence of low birth weight was higher, i.e., 15 out of $25(65.21 \%)$ and 8 out of $23(34.78 \%)$ had normal birth weight (Table 10). 16 out of $23(69.56 \%)$ cases had vaginal delivery, 5 out of 23 (21.735) underwent cesarean section. Rest 2 out of 23 (8.6\%) had instrumental vaginal delivery (Table 11). There was increased incidence of low birth weight infants $(47.82 \%)$ in case with severe

Table 3: Distribution of mothers according to modality of supplementation

\begin{tabular}{lll}
\hline Group & No. of patients & Percentage \\
\hline Group I & 41 & 64.06 \\
Group II & 23 & 35.93 \\
\hline
\end{tabular}

Group I-blood transfusion; group II-IV iron sucrose

Table 4: Distribution of antenatal mothers according to anemic status

\begin{tabular}{lll}
\hline Anemic status & No. of patients & Percentage \\
\hline Nonanemic & 143 & 33.01 \\
Mild anemic & 137 & 31.71 \\
Moderate anemic & 88 & 20.37 \\
Severe anemic & 64 & 14.18 \\
\hline
\end{tabular}

Nonanemic $\mathrm{Hb} \geq 10 \mathrm{~g} / \mathrm{dL}$; mild anemic $\mathrm{Hb}<10$ to $\leq 8 \mathrm{~g} / \mathrm{dL}$; moderate anemic $<7 \mathrm{~g} / \mathrm{dL}$; severe anemic $<7 \mathrm{~g} / \mathrm{dL}$ 
Increase in Hemoglobin Concentration after Administration of Intravenous Iron Sucrose

Table 5: Distribution of mothers with severe anemia according to residential status

\begin{tabular}{lll}
\hline Residence & No. of patients & Percentage \\
\hline Rural & 17 & 73.91 \\
Urban & 6 & 26.08 \\
\hline
\end{tabular}

Table 6: Distribution of antenatal mothers according to family income per month

\begin{tabular}{lcc}
\hline Family income/month & No. of patients & Percentage \\
\hline Poor $<$ Rs. 1,500/month & 16 & 69.56 \\
Low 1,500-5,000/month income & 6 & 26.08 \\
Middle income and a $\geq$ Rs. 5,000/ & 14 & 4.34 \\
month above & & \\
\hline
\end{tabular}

Table 7: Distribution of antenatal mothers according to literacy status

\begin{tabular}{lll}
\hline Literacy status & No. of patients & Percentage \\
\hline Illiterate & 3 & 13.4 \\
Just literate (signature only) & 9 & 39.13 \\
Primary (up to class IV) & 6 & 26.08 \\
Secondary (class V-class X) & 4 & 17.39 \\
HS and above $(>x)$ & 1 & 8.6 \\
\hline
\end{tabular}

Table 8: Distribution of antenatal mothers according to gravida

\begin{tabular}{lcl}
\hline Gravid & No. of patients & Percentage \\
\hline Primigravida & 8 & 34.78 \\
Multigravida & 15 & 65.21 \\
\hline
\end{tabular}

Table 9: Distribution of antenatal mothers with severe anemia according to side effect after IV iron therapy

\begin{tabular}{lll}
\hline Side effects & No. of patients & Percentage \\
\hline Nausea & 5 & 21.73 \\
Shivering & 3 & 13.4 \\
\hline
\end{tabular}

Table 10: Distribution of antenatal mothers according to birth weight of baby

\begin{tabular}{lll}
\hline Birth weight $(\mathrm{kg})$ & No. of patients & Percentage \\
\hline$<2.5$ & 15 & 65.21 \\
$\geq 2.5$ & 8 & 34.78 \\
\hline
\end{tabular}

Table 11: Distribution according to mode of delivery

\begin{tabular}{lcc}
\hline Mode of delivery & No. of patients & Percentage \\
\hline Vaginal delivery & 16 & 69.56 \\
Cesarean section & 5 & 21.73 \\
Instrumental vaginal delivery & 2 & 8.6 \\
\hline
\end{tabular}

anemia followed y IUGR babies (34.78\%) and premature babies (13.04\%). Incidence of stillborn babies (4.3\%) (Table 12). There is an association between the severity of anemia and maternal outcome with occurrence of PIH (21.73\%) and PPH (17.39\%) preterm labor accounts for (8.6\%) of cases (Table 13).

\section{Discussion}

Prevalence of iron-deficiency anemia during pregnancy shows declining trend in many developed countries, but in India the prevalence is still very high, between $33 \%$ and $100 \%$. According to $\mathrm{WHO}$, in developing countries the prevalence of anemia among the pregnant women averages (56\%), ranging between 35\% and
Table 12: Distribution of cases according to abnormal fetal outcome

\begin{tabular}{lcc}
\hline Abnormal outcome & No. of patients & Percentage \\
\hline Premature & 3 & 13.04 \\
Stillbirth & 1 & 4.3 \\
Low birth weight & 11 & 47.82 \\
IUGR & 8 & 34.78 \\
\hline
\end{tabular}

Table 13: Distribution of cases receiving IV iron sucrose according to abnormal pregnancy outcome

\begin{tabular}{llc}
\hline Abnormal outcome & No. of patients & Percentage \\
\hline PIH & 5 & 21.73 \\
Eclampsia & 0 & 0 \\
PPH & 4 & 17.39 \\
PROM & 0 & 0 \\
Preterm labor & 2 & 8.6 \\
\hline
\end{tabular}

$100 \%$ among different regions of world. In this study out of 8,390 antenatal cases, 432 were randomly screened for anemic status based on $\mathrm{Hb}$ level during their first visit to OPD, 143 (33.01\%) were found to be nonanemic and 289 were anemic. Among the anemic cases, 137 (31.71\%) mildly anemic, 88 (20.37\%) moderately anemic, $64(14.81 \%)$ severely anemic which is comparable to the study done by Riffat and Khan on association of severe anemia and adverse pregnancy outcome. It was found that frequency of anemia was $69.9 \%$ and that of severe anemia was $4.8 \% .{ }^{6}$ Low prevalence of severe anemia in Odisha may be due to availability and consumption of iron folate tablets. out of 64 antenatal cases with severe anemia, only 23 cases (35.93\%) had informed choice for IV iron sucrose therapy and hence recruited in the study. Rest 41 cases (64.06\%) received blood transfusion. This may be explained by a randomized trial by Ragip et al. which shows the disadvantages of intravenous treatment, i.e., cost, need for hospitalization or an outpatient setting and invasive nature of the procedure. ${ }^{7}$ In the present study, the severity of anemia is found to be maximum in the age group of 20-24 years (47.82\%) followed by $26.08 \%$ in the age group $25-29$ years. Similar results were obtained by Gautam et al. with most pregnant women (56.10\%) between 20 years and 24 years, followed by $25-29$ years $(21.1 \%)$, while $<20$ years accounted for $19.3 \%$ and only $3.5 \%$ were 30 years and above. ${ }^{8}$

Also, similar study by Nesimi et al. revealed average age of pregnant women with anemia to be $24.75 \pm 5.08$ years $<20$ years were $22.6 \%$ and $5.9 \%$ of the women were $\geq 35$ years group. 9,10 In the present study, antenatal cases with severe anemia belongs to rural area (73.915) and rest were residence of urban area (26.08\%), this in accordance with the study by Gautam et al., who observed high prevalence of anemia and its severity in rural are of Delhi. ${ }^{8}$ Present study shows that most of the cases (69.56\%) with severe anemia belongs to poor socioeconomic status having poor family income, $26.08 \%$ with low income and only $4.34 \%$ belong to middle income group. ${ }^{6}$ Similar study by Thangaleela, Vijayalakshmi and Saah et al. shows an inverse relationship of severity of anemia with income and educational status. ${ }^{11-13}$ The present study shows a close association between the severity of anemia and literacy status with most of the antenatal cases having less than primary education (26.08\%), illiterate (13.04\%), just literate (9\%) which is comparable to the study by Gautam et al., who observed that the most cases with severe anemia were educated only till high school or less. ${ }^{8}$ Nesimi Kisioglu et al. reported the highest percentage of women with primary education $78.7 \%$ with only $4.4 \%$ literate, 
$13.7 \%$ high school graduate and $3.2 \%$ were graduate of higher education. ${ }^{10}$ In the present study, multigravid women were more prone to anemia and its increased severity (65.21\%) and only $34.78 \%$ were primigravida which is comparable to the studies by Gautam et al. and Nesimi Kisioglu et al., showing increased severity of anemia with gravid $>2 ., 10$ out of $23(21.73 \%)$ cases complained of nausea and 3 (13.04\%) cases have shivering, rest with no side effect. Similar results were observed by Govan and Scott with minor side effects in $20 \%$ cases and severe adverse event in $1-2 \%$ cases. $^{14}$ Bashiri et al. reported the common side effects of intravenous iron sucrose are fever, shivering, nausea, change in test and hypotension in less than $1 \%$ cases and anaphylactoid reaction rarely occurred. ${ }^{15}$

Study by Silver and Breymann et al. found less than $0.002 \%$ cases with minor side effect and less than $0.5 \%$ cases with anaphylactoid reaction. ${ }^{9,16}$

In this study maximum number of cases (60.86\%) with increase in hemoglobin level after 4 weeks of IV iron sucrose supplementation to be $2.5-3 \mathrm{~g} / \mathrm{dL}$. Similar results were found by Perewusnyk et al., which showed mean increase in hemoglobin of $1.9 \mathrm{~g} / \mathrm{dL}$ after 7 days and $2.1-3.2 \mathrm{~g} / \mathrm{dL}$ after 14 days. The maximum mean daily increase in hemoglobin was $0.23 \mathrm{~g} / \mathrm{dL}^{17}$

We found close association of severity of anemia with fetal outcome with low birth weight babies accounting for $65.21 \%$. Rest $34.78 \%$ had babies with birth weight more than $2.5 \mathrm{~kg}$. Similar results were obtained by Lone et al. and Malhotra et al. which showed the increase risk of lower birth weight with severe anemia. ${ }^{18,19}$ Rehman et al. observed that the mean fetal birth weight was $2.47 \pm 0.331$ $\mathrm{kg}$ in anemic women and $3.31 \pm 0.297 \mathrm{~kg}$ in nonanemic women. ${ }^{20}$ The present study shows that most of the cases $69.56 \%$ had vaginal delivery and $21.73 \%$ underwent cesarean section.

We found abnormal fetal outcome in patients with severe anemia with low birth weight contributing to $47.82 \%$, prematurity $13.04 \%$, IUGR $34.7 \%$ and IUD $4.2 \%$. This observation is comparable to the study by Lone et al. which showed increased risk of all these complications. ${ }^{18} \mathrm{~A}$ retrospective analysis by Karasahin et al. found the rate of preterm delivery to be $9.9 \%$ and that of IUGR 3.4. ${ }^{21}$ The present study shows incidence of PIH 21.73\%, PPH 17.39\%, preterm labor $8.6 \%$ at delivery, which is comparable to the study by Kurki et al. ${ }^{22}$ Retrospective analysis by Emre et al. also revealed rate of pre-eclampsia $8.6 \%$ and preterm labor $9.9 \% .^{21}$

\section{Conclusion}

In conclusion IV iron therapy in pregnant women with severe anemia $(\mathrm{Hb}<7 \mathrm{mg} / \mathrm{dL})$ showed significant improvement in $\mathrm{Hb}$ level after 2 weeks with minimum side effects.

This is particularly beneficial in our country, where women indeed have minimal or nil iron stored. It also alleviates the requirement for blood transfusion, possibility of irregular intake of iron during pregnancy and fulfills the iron requirement beyond doubt even in minimum 3 weeks.

Though no serious adverse effects were observed in this study, it should be always kept in mind while administering as IV iron sucrose complex. This is a short study to comment about side effects of parenteral iron, and we need an extensive study to comment precisely of the above aspects.

As evident form this study intravenous iron sucrose is one of the promising iron preparations for use in obstetric as it is safe, effective and easy to handle by the physician.

\section{REFERENCES}

1. http://www.interscience.wiley.com/cochrane/.

2. Studd J. Progress in Obstetrics and Gynecology, 15th ed., 2002. pp. 104-116.

3. Desai P, Patel P. Medical Disorders in Pregnancy, 2005. pp. 284-285.

4. Danielson BG. Structure, chemistry and pharmacokinetics of intravenous iron agents. J Am Soc Nephrol 2004;15(Suppl 2):S93-S98.

5. http://www.answers.com/topic/iron-Sucrose injection: Cat; Health.

6. Jaleel R, Khan A. Severe anaemia and adverse pregnancy outcome. J Surg Pak 2008;13(4):147-150.

7. AI RA, Unlubilgin $E$, Kandemir $O$, et al. Intravenous versus oral iron for treatment of anaemia in pregnancy. Obstet Gynecol 2005;106(6):1335-1340. DOI: 10.1097/01.AOG.0000185260.82466.b4.

8. Gautam VP, Bansal Y, Taneja DK, et al. Prevalence of anaemia amongst pregnant women and its socio demographic associates in a rural area of Delhi. Indian J Community Med 2002;27(4):157.

9. Silver SB, Rodgers GM. Parenteral iron therapy options. Am J Hematol 2007;76(1):74-78.

10. Nesimi Kisioglu A, Ozturk M, Aytul Cakmak Z, et al. Anaemia prevalence and its affecting factors in pregnant women of Isparta Province. Biomed Res 2004;16(1):11-14.

11. Thangaleela T, Vijayalakshmi P. Prevalence of anaemia in pregnancy. Ind J Nutr Diet 1994;31:26-29.

12. Shah $S N$, Baksh $A$, Rauf $A$, et al. Incidence of iron deficiency anaemia in rual population of Kashmir. Indian J Public Health 1982;26(3):144-154.

13. Geelhoed D, Agadzi F, Visser L, et al. Maternal and fetal outcome after severe anaemia in pregnancy in rural Ghana. Acta Obstet Gynecol Scand 2006;85(1):49-55. DOI: 10.1080/00016340500334794.

14. Scott JM, Govan AD. Anaemia of pregnancy treatment with intravenous iron. 1951. Eur J Obstet Gynecol Reprod Biol 2005;123(Suppl 2): S29-S32. DOI: 10.1016/S0301-2115(05)80404-X.

15. Bashiri A, Burstein $E$, Sheiner $E$, et al. Anaemia during pregnancy and treatment with intravenous iron. Eur J Obstet Gynecol Reprod Biol 2003;110(1):2-7. DOI: 10.1016/S0301-2115(03)00113-1.

16. Breymann C. Eur J Obstet Gynecol Reprod Biol 2005;123(Suppl 2): S1-S2.

17. Perewusnyk G, Huch R, Huch A, et al. Parenteral iron therapy in obstetrics: 8 years, experience with iron- sucrose complex. Perinatal physiology Unit, Department of Obstetrics, Zurich University Hospital, Switzerland, 2002.

18. Lone FW, Qureshi RN, Emanuel F. Maternal anaemia and its impact on perinatal outcome. Trap Med Int Health 2004;9(4):486-490. DOI: 10.1111/j.1365-3156.2004.01222.x.

19. Malhotra M, Sharma JB, Batra S, et al. Maternal and perinatal outcome in varying degree of anaemia. Int J Gynaecol Obstet 2002;79(2): 93-100. DOI: 10.1016/S0020-7292(02)00225-4.

20. Rehman A, Ghazanfar B, Soomso N. Effect of maternal anaemia in fetal outcome i.e. Apgar score and birth weight. Pak J Surg Oct 2005;21(2):102-105.

21. Karasahin E, Cyhan ST, Goktolga U, et al. Maternal anaemia and perinatal outcome. Perinat J 2007;15(3):127-130.

22. Kurki T, Sivonen A, Renkonen OV, et al. Bacterial vaginosis in early pregnancy and pregnancy outcome. Obstet Gynecol 1992;80(2): 173-177. 